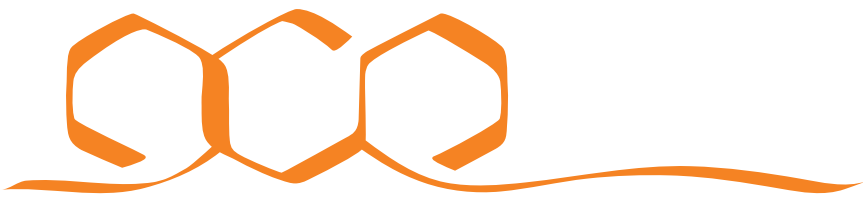 \\ COMMUNICATIONS CHEMISTRY
}

ARTICLE

https://doi.org/10.1038/s42004-019-0156-x OPEN

\section{Nanostructured bismuth vanadate/tungsten oxide photoanode for chlorine production with hydrogen generation at the dark cathode}

Alan M. Rassoolkhani ${ }^{1}$, Wei Cheng ${ }^{1}$, Joun Lee ${ }^{1}$, Austin McKee ${ }^{1}$, Jonathan Koonce ${ }^{1}$, Joel Coffel', Abdulsattar H. Ghanim¹, Gary A. Aurand ${ }^{1}$, Chung Soo Kim², Woon Ik Park², Hyunsung Jung ${ }^{2}$ \& Syed Mubeen ${ }^{1}$

Photoelectrooxidation of chloride ions to chlorine with co-production of hydrogen by water reduction has been proposed as a means of decreasing the net solar hydrogen production cost. So far, however, most such solar-to-chlorine production systems use cost-prohibitive materials and/or show rather small faradaic yield or stability. Here we report the development of earth-abundant, nanostructured bismuth vanadate/tungsten oxide $\left(\mathrm{BiVO} \mathrm{O}_{4} / \mathrm{WO}_{3}\right)$ photoanode assemblies that operate in acidic sodium chloride solution ( $\mathrm{pH} \mathrm{1;4M)}$ to produce chlorine while generating hydrogen at the dark cathode. We show that electrodeposition of $20 \mathrm{~nm} \mathrm{WO}$ coating protects $\mathrm{BiVO}_{4}$ from harsh $\mathrm{pH}$ and oxidative environments while being catalytically active for chlorine evolution. The heterostructured $\mathrm{BiVO} \mathrm{O}_{4} / \mathrm{WO}_{3}$ photoanodes yield average photocurrent densities of $2.5 \pm 0.3 \mathrm{~mA} \mathrm{~cm}^{-2}$ at $1.42 \mathrm{~V}_{\mathrm{RHE}}$ (Reversible Hydrogen Electrode) under 1 sun illumination. After two hours of continuous illumination, the best performing devices demonstrate faradaic efficiencies of $85 \%$ for chlorine production and $\sim 100 \%$ for hydrogen production.

\footnotetext{
${ }^{1}$ Department of Chemical and Biochemical Engineering, University of lowa, lowa City, IA 52242, USA. ${ }^{2}$ Nano-Convergence Materials Center, Korea Institute of Ceramic Engineering and Technology, Jinju-si, Republic of Korea 52851. Correspondence and requests for materials should be addressed to S.M. (email: syed-mubeen@uiowa.edu)
} 
$\mathrm{H}$ ydrogen is an important industrial chemical and fuel with worldwide production capacity of approximately 50 MMT $\mathrm{yr}^{-11}$. Photoelectrochemical (PEC) water splitting offers the potential to produce $\mathrm{H}_{2}$ sustainably from sunlight and water. In the past few decades, revolutionary advances have been made in developing PEC water splitting systems that can produce $\mathrm{H}_{2}$ with solar-to- $\mathrm{H}_{2}$ (STH) efficiencies exceeding $10 \%{ }^{2,3}$. While efforts to lower the $\mathrm{H}_{2}$ production cost using low-cost materials have been extensively pursued, a key technical and economic challenge to solar water splitting processes is the 4 electron oxidation of water which is slow kinetically and results in the production of limited economic value $\mathrm{O}_{2}$ (Eq. 1$)^{4-7}$.

$$
2 \mathrm{H}_{2} \mathrm{O} \rightarrow \mathrm{O}_{2}+4 \mathrm{H}^{+}+4 e^{-} E^{o}=1.23 V_{R H E}
$$

Identifying cost-effective reactions for photoelectrooxidation could open up new pathways to lower the net solar $\mathrm{H}_{2}$ production cost. Photoelectrooxidation of chloride ions to chlorine (Eq. 2) accompanied by water reduction at the cathode to produce $\mathrm{H}_{2}$, could provide an attractive, cost-effective alternative to water oxidation $^{8-10}$.

$$
2 \mathrm{Cl}^{-} \rightarrow \mathrm{Cl}_{2}+2 e^{-} \mathrm{E}^{o}=1.42 \mathrm{~V}_{\mathrm{RHE}}
$$

Today chlorine has a market value of $\$ 12.7$ billion ( $\$ 240$ ton $^{-1}$ ) and yearly production rates of $53 \mathrm{MMT}^{11}$. For this process, each $\mathrm{kg}$ of hydrogen produced could potentially yield $35 \mathrm{~kg}$ of chlorine which could be sold to offset the cost of the overall process. Furthermore, 2 electron oxidation of chloride ions is kinetically and energetically more favorable compared to 4 electron water oxidation and can be carried out efficiently using nonplatinum group metals 6,11 .

Recently, a few reports have explored the possibility of producing chlorine photoelectrochemically, however, all attempts have been hindered by: (1) low chlorine yield ${ }^{12}$, and/or (2) expensive and unstable systems ${ }^{13,14}$. To obtain high chlorine yields, the light absorber should be stabilized in an acidic environment to mitigate the production of oxygen through either (1) catalytic conversion of $\mathrm{H}_{2} \mathrm{O}$ to $\mathrm{O}_{2}$ using photogenerated holes (Eqs. 1) decomposition of dissolved chlorine to form $\mathrm{O}_{2}$ (Eqs. 3 and 4).

$$
\begin{gathered}
\mathrm{Cl}_{2}+\mathrm{H}_{2} \mathrm{O} \rightarrow \mathrm{HClO}+\mathrm{Cl}^{-}+\mathrm{H}^{+} \\
\mathrm{HClO} \rightarrow \mathrm{H}^{+}+\mathrm{Cl}^{-}+\frac{1}{2} \mathrm{O}_{2}
\end{gathered}
$$

The latter has been shown to be the predominant reaction pathway in neutral to basic solutions ${ }^{12,14}$. Furthermore, for large scale application, these electrodes should be made of earth abundant elements.

The focus of the current work is to carry out chloride oxidation in acidic conditions ( $\mathrm{pH}$ 1) using earth-abundant nanoporous bismuth vanadate $\left(\mathrm{BiVO}_{4}\right)$ as the light absorber, and use electrons provided from the oxidation step to generate hydrogen at the dark cathode. $\mathrm{BiVO}_{4}$ has recently emerged as a promising low-cost photoanode for solar water oxidation due to its favorable band gap $\left(\mathrm{E}_{\mathrm{g}}=2.4 \mathrm{eV}\right)$ and conduction band $(\mathrm{CB})$ edge location $(0.1 \mathrm{~V}$ vs. Reversible Hydrogen Electrode $\left.\left(\mathrm{V}_{\mathrm{RHE}}\right)\right)^{15,16} \cdot \mathrm{BiVO}_{4}$ is chemically stable in neutral or slightly basic $\mathrm{pH}$ conditions ${ }^{17,18}$, however, for chlorine production it should be stabilized in an acidic environment ${ }^{6,11}$. Here we show that electrodeposition of amorphous tungsten oxide $\left(\mathrm{WO}_{3}\right)$ provides conformal coatings on nonporous crystalline $\mathrm{BiVO}_{4}$ and prevents photocorrosion in the acidic environment. Amorphous $\mathrm{WO}_{3}$ was selected as stabilization element because of its: (i) large band gap ( $>3 \mathrm{eV}$; thereby transmitting most of the incident light to $\left.\mathrm{BiVO}_{4}\right)^{19}$; (ii) good chemical and electrochemical stability under acidic conditions ${ }^{20,21}$; (iii) selective electrocatalytic activity for $\mathrm{Cl}^{-}$oxidation over $\mathrm{H}_{2} \mathrm{O}$ oxidation $^{22,23}$; and, (iv) ability to transfer holes through gap states in its band structure ${ }^{24}$. $\mathrm{A} \mathrm{WO}_{3}$ film of thickness $20 \mathrm{~nm}$ is sufficient to prevent $\mathrm{BiVO}_{4}$ corrosion while being thin enough to transmit most of the incident light to $\mathrm{BiVO}_{4}$. The bestperforming $\mathrm{BiVO}_{4} / \mathrm{WO}_{3}$ photoelectrode assemblies achieve a limiting photocurrent density of $2.8 \mathrm{mAcm}^{-2}$ and operate sustainably for more than three hours with faradaic efficiencies of $85 \%$ for $\mathrm{Cl}^{-}$oxidation. To the best of our knowledge, it is the highest reported so far for this material ${ }^{5}$.

\section{Results}

Synthesis and characterization. Details of the fabrication of $\mathrm{BiVO}_{4} / \mathrm{WO}_{3}$ photoanodes are provided in the methods section. Briefly, the $\mathrm{BiVO}_{4} / \mathrm{WO}_{3}$ nanostructured films were deposited on conductive fluorine-doped tin oxide (FTO) coated glass substrate using a two-step process. The first step is the fabrication of crystalline $\mathrm{BiVO}_{4}$ light absorber unit following previously reported methods ${ }^{17}$, where electrodeposited bismuth oxyiodide (BiOI) is used as a precursor to form $\mathrm{BiVO}_{4}$. (Fig. 1a, c) shows a top view and cross-sectional scanning electron microscopy (SEM) images of the bare $\mathrm{BiVO}_{4}$ electrode. The SEM images displayed a nanoporous architecture for $\mathrm{BiVO}_{4}$ with interconnected particles of approximately $90 \mathrm{~nm}$ in diameter. A nanoporous architecture with minority carrier diffusion lengths on the order of $100 \mathrm{~nm}$ (as determined by the particle diameter) has been shown to enhance charge separation efficiency while providing a large contact surface area at the $\mathrm{BiVO}_{4} /$ electrolyte interface ${ }^{17,18}$.

The $\mathrm{WO}_{3}$ layer ( $20 \mathrm{~nm}$ thick) was subsequently electrodeposited on $\mathrm{BiVO}_{4}$ (Fig. 1b) using a peroxytungstic acid solution ${ }^{20}$. It is to be noted that the tungsten oxide deposition was carried in dark at pH 2 under cathodic conditions to prevent photooxidative corrosion of $\mathrm{BiVO}_{4}{ }^{25-27}$. We did not observe any chemical and/ or electrochemical corrosion of the $\mathrm{BiVO}_{4}$ for the deposition durations investigated in this study. Remarkably, a conformal deposition of $\mathrm{WO}_{3}$ on the $\mathrm{BiVO}_{4}$ electrode was observed down to the base of the particle while preserving the nanoporous architecture for efficient carrier extraction (Fig. 1d). The thickness of the $\mathrm{WO}_{3}$ layers was tuned by adjusting the charge passed during electrodeposition (Supplementary Fig. 1). The optimum thickness was probed by comparing their photoelectrochemical behavior (Supplementary Fig. 2). Under the optimized condition, passing $100 \mathrm{mC} \mathrm{cm}^{-2}$ of charge at $-0.5 \mathrm{~V}$ vs. silver/silver chloride (Ag/AgCl) electrode yielded $\mathrm{WO}_{3}$ thickness of $20 \mathrm{~nm}$. As shown later, a $20 \mathrm{~nm}$ thick $\mathrm{WO}_{3}$ film was sufficient to stabilize $\mathrm{BiVO}_{4}$ in acidic $\mathrm{pH}$ conditions while transmitting most of the incident light to $\mathrm{BiVO}_{4}$ (Supplementary Fig. 3). Thicker films were not found to increase sample stability with the only observable effect being a decrease in limiting current density likely as a result of parasitic light absorption or carrier recombination through the $\mathrm{WO}_{3}$ film. The overall thickness of the $\mathrm{BiVO}_{4} / \mathrm{WO}_{3}$ films as measured by the cross-sectional SEM images was about $600 \mathrm{~nm}$ (Fig. 1c, d). This thickness was selected based on prior reports which showed enhanced light absorption for $600 \mathrm{~nm}$ thick $\mathrm{BiVO}_{4}$ nanostructures with minimal charge recombination losses ${ }^{16}$.

The nanostructured $\mathrm{BiVO}_{4} / \mathrm{WO}_{3}$ films were further characterized using high resolution transmission electron microscopy (HRTEM), energy-dispersive $\mathrm{x}$-ray spectroscopy (EDS) and x-ray photoelectron spectroscopy (XPS). (Fig. 1e, f) shows HRTEM images and fast Fourier transform (FFT) patterns (Fig. 1e, f, inset) of both bare $\mathrm{BiVO}_{4}$ particle and $\mathrm{BiVO}_{4}$ coated with $\mathrm{WO}_{3}$. Lowmagnification images are provided in the supplementary information (Supplementary Fig. 4). The HRTEM image revealed a crystalline structure for bare $\mathrm{BiVO}_{4}$ (Fig. 1e) with a lattice spacing of $0.307 \mathrm{~nm}$, corresponding to the (112) planes of $\mathrm{BiVO}_{4}$ 

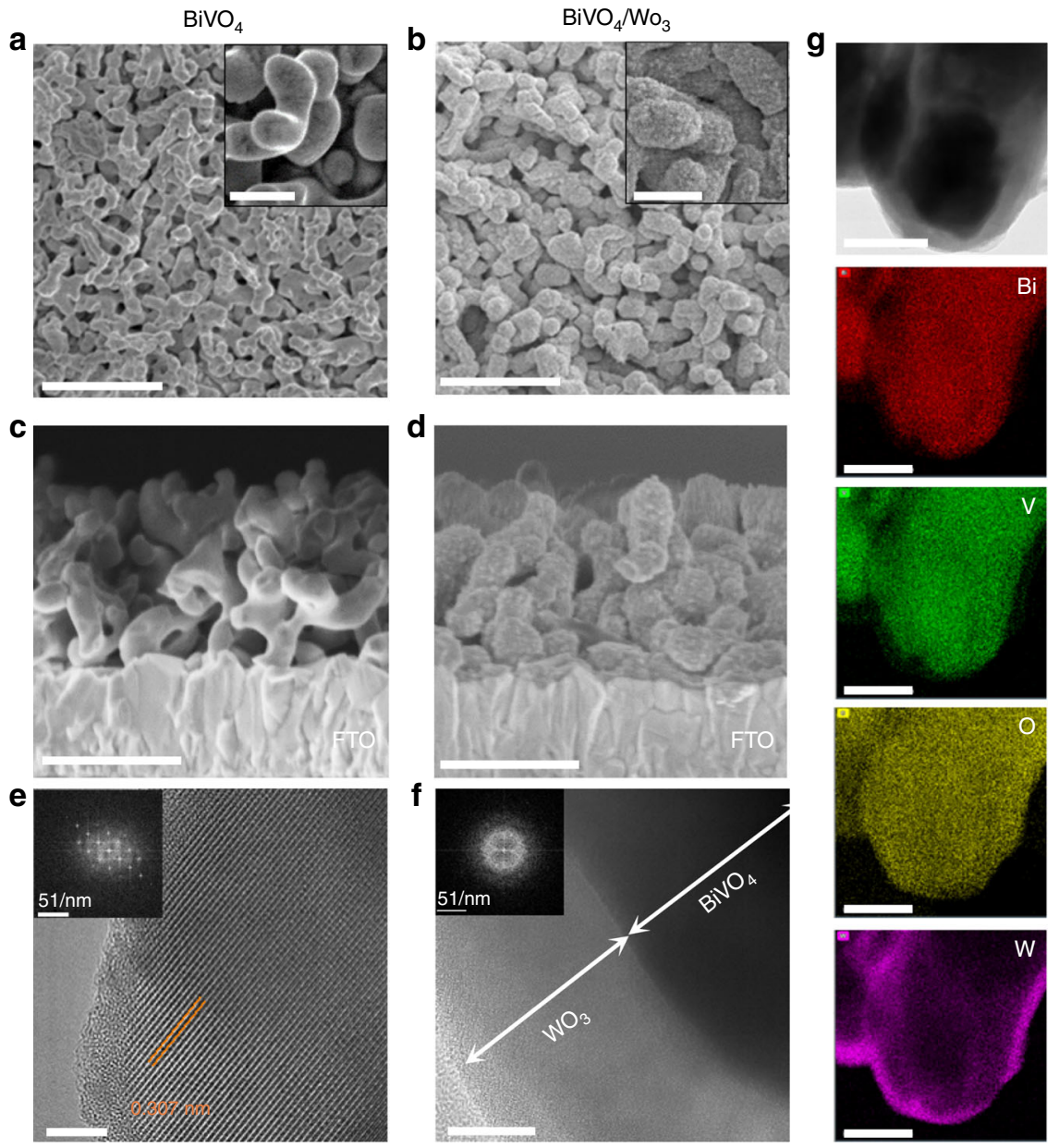

Fig. 1 Structural characterization of $\mathrm{BiVO}_{4}$ and $\mathrm{BiVO}_{4} / \mathrm{WO}_{3}$. Top view scanning electron microscopy (SEM) images of $\mathbf{a}$ bare $\mathrm{BiVO}_{4}$ and $\mathbf{b}$ BiVO $\mathrm{B}_{4}$ electrode coated with $20 \mathrm{~nm}$ thick $\mathrm{WO}_{3}$ (scale bar $-1 \mu \mathrm{m}$ ) with inset showing high magnification SEM images (scale bar - $200 \mathrm{~nm}$ ). Cross sectional SEM images of c bare $\mathrm{BiVO}_{4}$ and $\mathbf{d} \mathrm{BIVO}_{4} / \mathrm{WO}_{3}$ (scale bar $-500 \mathrm{~nm}$ ). High resolution transmission electron microscopy (HRTEM) images of e bare BiVO ${ }_{4}(\mathrm{scale}$ bar $5 \mathrm{~nm}$ ) and $\mathbf{f} \mathrm{BIVO}_{4} / \mathrm{WO}_{3}$ (scale bar - $10 \mathrm{~nm}$ ) with inset showing fast Fourier transform (FFT) pattern. $\mathbf{g}$ Energy dispersive x-ray spectroscopy (EDS) elemental mapping of the core shell $\mathrm{BiVO}_{4} / \mathrm{WO}_{3}$ (scale bar - $75 \mathrm{~nm}$ )

(JCPDS file no. 14-0688). HRTEM images of the coated samples (Fig. 1f) showed a clear interface between the $\mathrm{BiVO}_{4}$ core and $\mathrm{WO}_{3}$ shell with $\mathrm{WO}_{3}$ film coated along the surface of the $\mathrm{BiVO}_{4}$ particle with a uniform thickness of $20 \mathrm{~nm}$. The FFT pattern indicated that the deposited $\mathrm{WO}_{3}$ film was amorphous in nature (Fig. 1f, inset). EDS elemental mapping (Fig. 1g) revealed the compositional variation of the $\mathrm{BiVO}_{4} / \mathrm{WO}_{3}$ particle. The $\mathrm{W}$ signal was recorded from the entire area, supporting the conformal coating geometry. Strong Bi and V signals were obtained from the center region further indicating the existence of the core-shell architecture of the $\mathrm{BiVO}_{4} / \mathrm{WO}_{3}$ particle. No $\mathrm{W}$ signal was detected from the bare $\mathrm{BiVO}_{4}$ films (Supplementary Fig. 5). The chemical nature of the $\mathrm{BiVO}_{4} / \mathrm{WO}_{3}$ electrode was investigated using XPS (Supplementary Fig. 6). The characteristic Bi $4 \mathrm{f}$ and V $2 \mathrm{p}$ peaks were identified in the survey spectra of the bare $\mathrm{BiVO}_{4}$ sample. For the tungsten coated particles symmetric $\mathrm{W}$ 4f peaks were identified at $37.7 \mathrm{eV}$ and $35.6 \mathrm{eV}$ indicative of the trioxide species (Supplementary Fig. 7) ${ }^{24}$.

PEC characterization. The PEC properties of the $\mathrm{BiVO}_{4} / \mathrm{WO}_{3}$ photoanodes were characterized in a three-electrode configuration with $\mathrm{BiVO}_{4} / \mathrm{WO}_{3}$ as working electrode, and $\mathrm{Ag} / \mathrm{AgCl}$ reference electrode and $\mathrm{Pt}$ as counter electrode separated using a glass frit. Photoelectrooxidation of chloride ions using $\mathrm{BiVO}_{4} / \mathrm{WO}_{3}$ photoanode assembly can be explained conceptually by referring to (Fig. 2a, b). Upon illumination, photogenerated holes in $\mathrm{BiVO}_{4}$ are carried away to the surface through amorphous $\mathrm{WO}_{3}$ films where it oxidizes chloride ions to chlorine (Fig. 2b). The electrons provided from the oxidation step are transferred through an external circuit to a dark Pt cathode for hydrogen production.

To confirm that the amorphous $\mathrm{WO}_{3}$ layer does not interfere with the photogenerated carrier transport properties of underlying $\mathrm{BiVO}_{4}$ films, the PEC performance of $\mathrm{BiVO} / \mathrm{WO}_{3}$ photoanode was first investigated in a phosphate buffer solution containing sodium sulfite as a hole scavenger. Prior studies have shown that sulfite oxidation is kinetically and thermodynamically favorable on $\mathrm{BiVO}_{4}$ electrodes and can be used as a benchmark electrolyte to decouple charge separation efficiency from kinetic losses ${ }^{16-18}$. Figure $2 \mathrm{c}$ shows the typical photocurrent densities obtained for sulfite oxidation as a function of the applied potential under 1 sun illumination (AM 1.5G; $100 \mathrm{mWcm}^{-2}$ ). All potentials are referenced to reversible hydrogen electrode $\left[\mathrm{V}_{\mathrm{RHE}} ; \mathrm{V}_{\mathrm{RHE}}=\right.$ $\mathrm{V}_{\mathrm{Ag} / \mathrm{AgCl}}+0.197 \mathrm{~V}+0.059 \mathrm{pH}$ ] and all PEC results shown here are average values obtained from three samples. An average photocurrent density of $3 \mathrm{~mA} \mathrm{~cm}-2$ was achieved for $\mathrm{BiVO}_{4} / \mathrm{WO}_{3}$ films at $1.2 \mathrm{~V}_{\mathrm{RHE}}$. Photocurrent densities of $\mathrm{BiVO}_{4} / \mathrm{WO}_{3}$ were within $\pm 0.1 \mathrm{mAcm}^{-2}( \pm 3 \%)$ compared to the bare $\mathrm{BiVO}_{4}$ electrode surface (Fig. $2 c$, green trace) indicating that the amorphous $\mathrm{WO}_{3}$ prepared via electrodeposition technique functions efficiently as a hole transport layer with minimal resistive losses. 
a
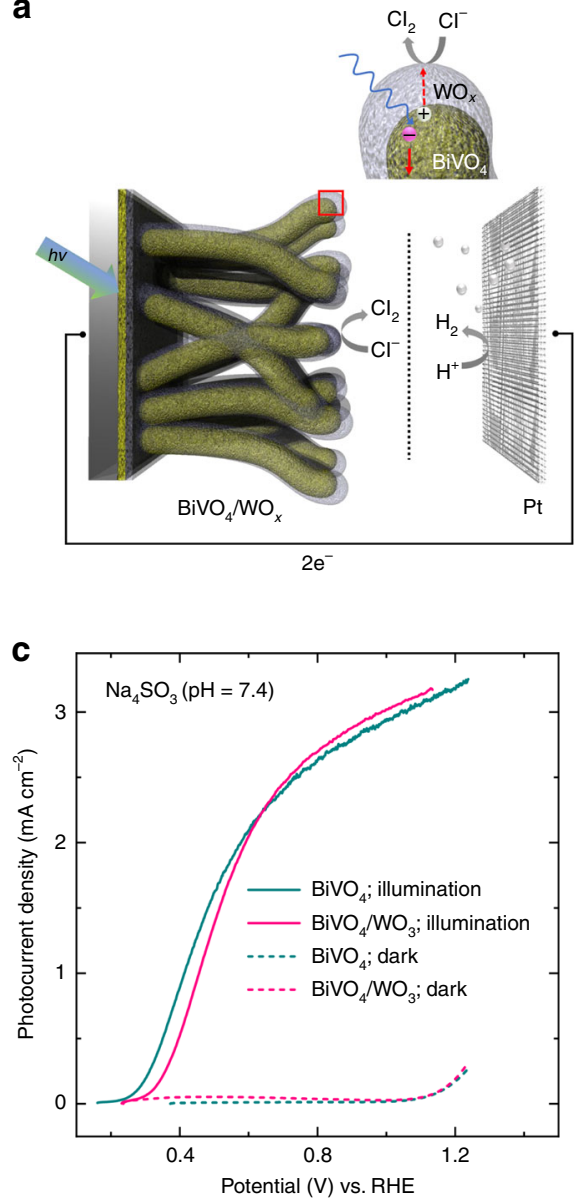

b

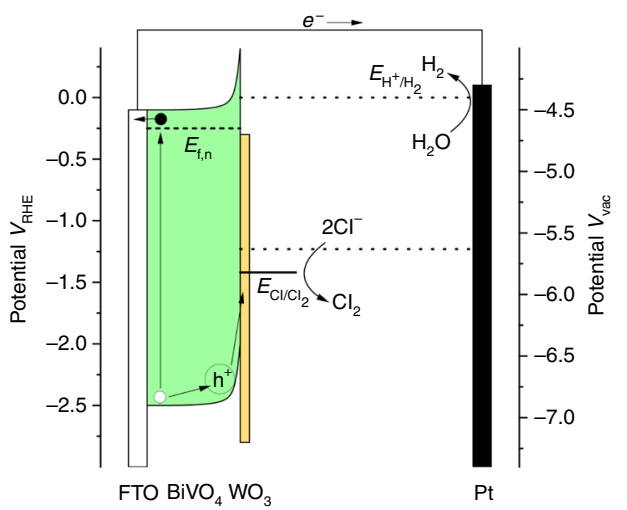

d

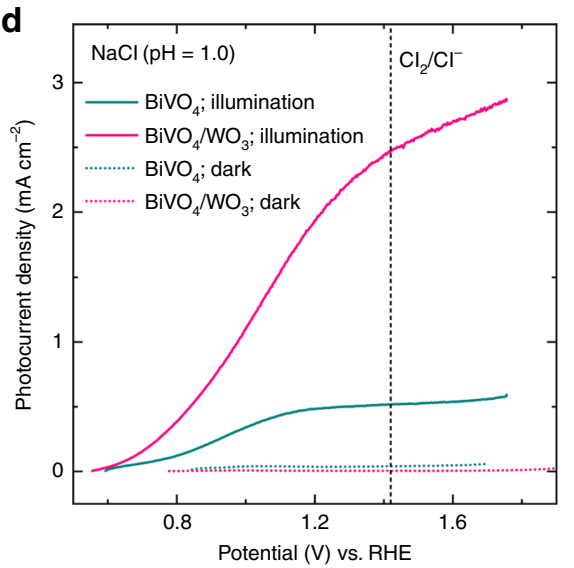

Fig. 2 Photoelectrochemical performance of $\mathrm{BiVO}_{4}$ and $\mathrm{BiVO}_{4} / \mathrm{WO}_{3}$. a Schematic showing the overall reaction scheme and $\mathbf{b}$ charge transfer process at the photoanode. Current density - potential $\left(\mathrm{V}_{\mathrm{RHE}}\right)$ plots of $\mathrm{BiVO}_{4}$ and $\mathrm{BiVO}_{4} / \mathrm{WO}_{3}$ coated samples in $\mathbf{c}$ sodium sulfite hole scavenger solution and $\mathbf{d}$ in $4 \mathrm{M} \mathrm{NaCl} \mathrm{pH} 1$ solution

The PEC performance of $\mathrm{BiVO}_{4} / \mathrm{WO}_{3}$ films for chloride oxidation was characterized in $4 \mathrm{M} \mathrm{NaCl}$ solution with $\mathrm{pH}$ adjusted to 1 using $\mathrm{HCl}$. Figure $2 \mathrm{~d}$ shows photocurrent density-potential plots for bare $\mathrm{BiVO}_{4}$ and $\mathrm{BiVO}_{4} / \mathrm{WO}_{3}$ photoanodes after 10 sweeps. All plots are average of three different samples and the depicted data are from the $10^{\text {th }}$ linear sweep voltammetric cycle (Fig. 2d). All 10 sweeps for a given $\mathrm{BiVO}_{4}$ and $\mathrm{BiVO}_{4} / \mathrm{WO}_{3}$ sample can be found in Supplementary Fig. 8. Each cycle was scanned at a rate of $20 \mathrm{mVs}^{-1}$, followed by a rest period of $30 \mathrm{~s}$. In the absence of light, negligible anodic current densities $\left(i<10 \mu \mathrm{Acm}^{-2}\right)$ were observed for bare $\mathrm{BiVO}_{4}$ and $\mathrm{BiVO}_{4} / \mathrm{WO}_{3}$ samples (Fig. 2d, dashed lines). Upon illumination, the $\mathrm{BiVO}_{4} /$ $\mathrm{WO}_{3}$ photoanode assembly showed a limiting photocurrent density of $2.8 \mathrm{mAcm}^{-2}$ at $1.6 \mathrm{~V}_{\mathrm{RHE}}$. The limiting photocurrent densities obtained were only slightly lower $\left(\leq 0.2 \mathrm{mAcm}^{-2}\right)$ than those observed for the same electrodes in contact with the sulfite solution indicating that the chloride oxidation could be carried out efficiently using holes transported to the surface of amorphous $\mathrm{WO}_{3}$ layer without the need for an additional catalyst.

We also conducted incident photon to current efficiency (IPCE) measurements of the $\mathrm{WO}_{3}$ coated samples at $1.42 \mathrm{~V}_{\mathrm{RHE}}$ (Supplementary Fig. 9). Integrating the IPCE values yielded a photocurrent density of $2.61 \mathrm{~mA} \mathrm{~cm}^{-2}$ which is within $5 \%$ of the measured photocurrent obtained under simulated sunlight experiments (Fig. 2d, magenta trace). The onset potential defined as the potential at which anodic photocurrent density reaches $20 \mu \mathrm{Acm}^{-2}$ - was $0.67 \mathrm{~V}_{\mathrm{RHE}}$ for the $\mathrm{BiVO}_{4} / \mathrm{WO}_{3}$ sample.
This resulted in an estimated photovoltage of $0.75 \mathrm{~V}$ after subtracting the thermodynamic potential requirement for chlorine production $\left(1.42 \mathrm{~V}_{\mathrm{RHE}}\right)$. For the bare $\mathrm{BiVO}_{4}$ sample, the photocurrents decreased with cycle number with the $10^{\text {th }}$ cycle showing a maximum photocurrent density of $0.75 \mathrm{mAcm}^{-2}$ at 1.6 $\mathrm{V}_{\mathrm{RHE}}$. The as deposited $\mathrm{WO}_{3}$ film themselves were found to have negligible photoactivity which supports their primary role in facilitating charge transport as opposed to electron hole pair generation (Supplementary Fig. 10).

Stability and product analysis. The durability of the photoanodes for chloride oxidation was assessed by measuring the photocurrent density as a function of time at a constant external bias of $1.42 \mathrm{~V}_{\mathrm{RHE}}$ (Fig. 3a). Bare $\mathrm{BiVO}_{4}$ demonstrated higher initial photocurrents compared to $\mathrm{WO}_{3}$ coated samples however the current rapidly declined over the first few minutes indicating the high activity is due to the rapid photo-corrosion process as seen by the complete disappearance of the film after $15 \mathrm{~min}$ (Supplementary Fig. 11). Prior studies have shown that $\mathrm{BiVO}_{4}$ when operated in chloride electrolytes below $\mathrm{pH} 3$ oxidizes to $\mathrm{BiOCl}$ with the dissolution of vanadium resulting in material degradation ${ }^{25-28}$. On the contrary, $\mathrm{BiVO}_{4}$ samples with $\mathrm{WO}_{3}$ layer as thin as $20 \mathrm{~nm}$ exhibited enhanced stability maintaining $>95 \%$ of initial photocurrent density after $3 \mathrm{~h}$ of continuous illumination (the duration of these stability tests).

Analysis of the $\mathrm{BiVO}_{4} / \mathrm{WO}_{3}$ electrodes post $\mathrm{PEC}$ operation by HRTEM-EDS revealed that the $\mathrm{BiVO}_{4}$ core layer was intact after 

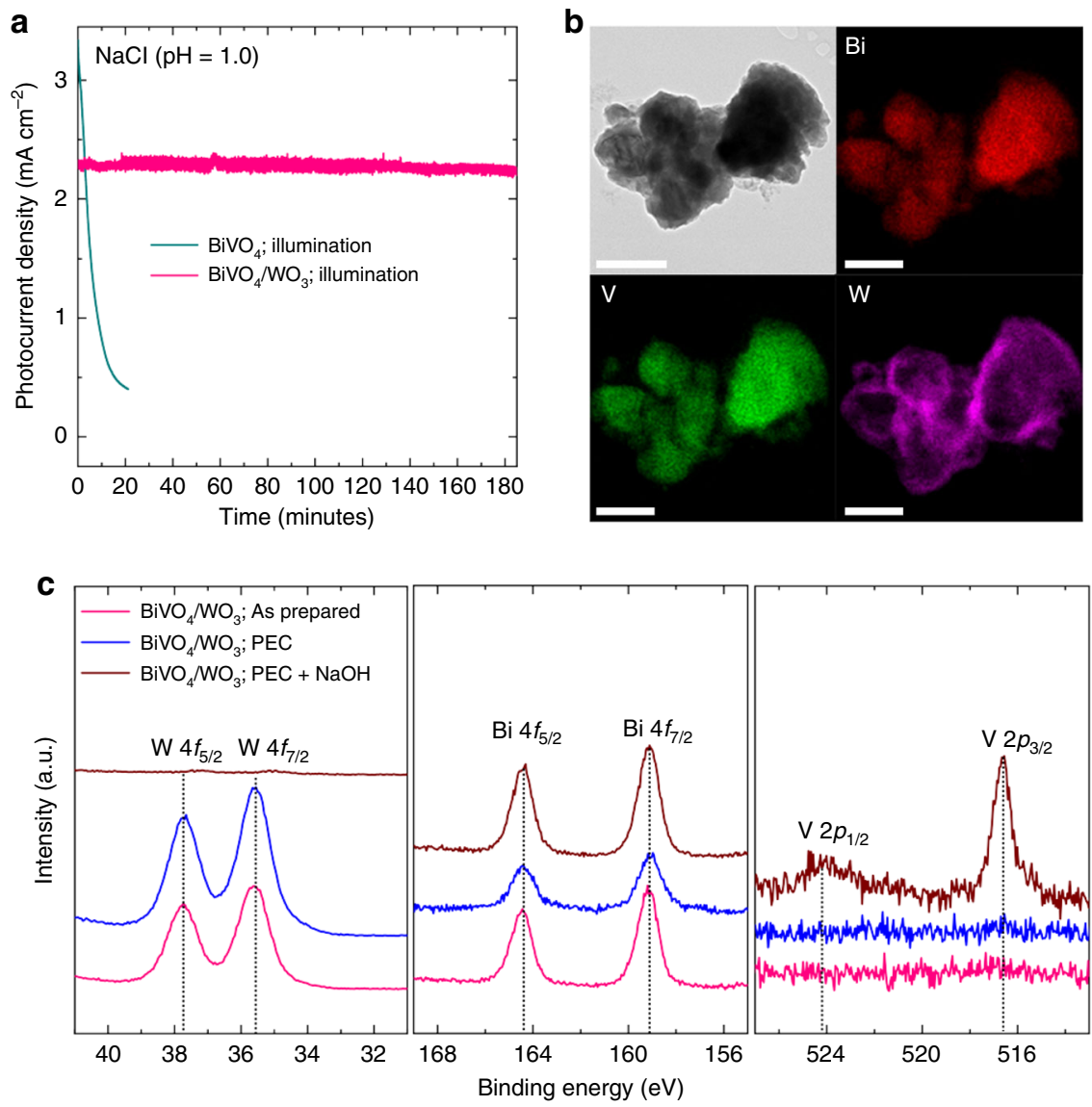

Fig. 3 Photoelectrochemical (PEC) stability of $\mathrm{BiVO}_{4}$ and $\mathrm{BiVO}_{4} / \mathrm{WO}_{3}$. a Photocurrent density - time transient plot for $\mathrm{BiVO}_{4}$ and $\mathrm{BiVO} \mathrm{V}_{4} / \mathrm{WO}_{3}$ sample for chloride oxidation at $1.42 \mathrm{~V}_{\mathrm{RHE}}$ under 1 sun illumination. b Energy dispersive $\mathrm{x}$-ray spectroscopy (EDS) elemental mapping of the $B i V \mathrm{O}_{4} / \mathrm{WO}_{3}$ structure post operation with its corresponding transmission electron microscopy image (150 nm scale bar). c Core level x-ray photoelectron spectroscopy (XPS) scans of $\mathrm{W}, \mathrm{Bi}$, and $\mathrm{V}$ as prepared (pink trace) and after $\mathrm{PEC}$ operation (blue trace). Core level scans of $\mathrm{W}, \mathrm{Bi}$, and $\mathrm{V}$ after removal of $\mathrm{WO}_{3}$ layer post operation is also shown (brown trace)

PEC operation with $\mathrm{W}$ signal present throughout and more pronounced at the edge of the particles (Fig. 3b). Furthermore, no change in chemical environment of the $\mathrm{WO}_{3}$ layer was observed post operation via XPS (Fig. 3c). To obtain chemical information of the underlying $\mathrm{BiVO}_{4}$ layer post-operation, the $\mathrm{WO}_{3}$ layer after PEC operation was removed by soaking it in sodium hydroxide solution for $15 \mathrm{~min}$. Within this time frame, the $\mathrm{NaOH}$ only etches $\mathrm{WO}_{3}$ layer without affecting the underlying $\mathrm{BiVO}_{4}$. Core level XPS scans of the $\mathrm{Bi} 4 \mathrm{f}$ and $\mathrm{V} 2 \mathrm{p}$ scans showed peaks identical to that of the bare $\mathrm{BiVO}_{4}$ electrode (Fig. $3 \mathrm{c}$ ). The above results unequivocally demonstrate that the electrodeposited amorphous $\mathrm{WO}_{3}$ layer could potentially offer a simple and scalable route to protect the underlying nanostructured $\mathrm{BiVO}_{4}$ when operated in acidic media, while still allowing for efficient transport of holes between the solution and the $\mathrm{BiVO}_{4}$ electrode. Although $\mathrm{WO}_{3}$ coated $\mathrm{BIVO}_{4}$ samples remain visibly intact for longer duration stability runs $(\sim 12 \mathrm{~h})$, a linear decrease in photocurrent ( $10 \%$ normalized photocurrent $\left.\mathrm{h}^{-1}\right)$ was observed after three hours. We attribute this drop-in performance due to deactivation of $\mathrm{WO}_{3}$ due to accumulation of peroxo species at the surface as reported previously $22,29,30$.

After $2 \mathrm{~h}$ of constant potential $\left(1.42 \mathrm{~V}_{\mathrm{RHE}}\right)$ PEC runs, the collected products were analyzed to determine the faradaic efficiency of the process (Fig. 4). $\mathrm{H}_{2}$ and $\mathrm{O}_{2}$ were investigated using gas chromatography. Chlorine was swept from the electrolyte solution by a slow helium $(\mathrm{He})$ purge into a potassium iodide solution, and the amount of dissolved chlorine was then

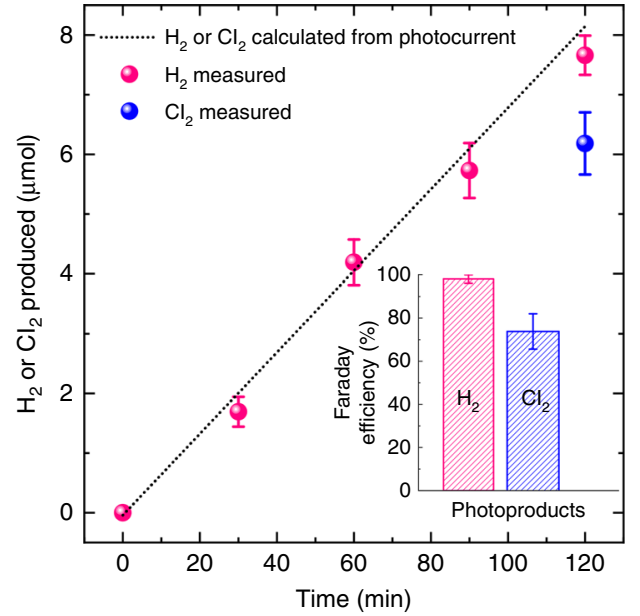

Fig. 4 Product Quantification. Photogenerated $\mathrm{Cl}_{2}$ and $\mathrm{H}_{2}$ measured over the course of $2 \mathrm{~h}$ under 1 sun illumination. Inset shows faradaic efficiency for $\mathrm{H}_{2}$ and $\mathrm{Cl}_{2}$ production. Error bars represent the standard deviation for five different samples

measured by Iodometric titration ${ }^{31}$. Prior to the stability tests, the system was purged with a pure He stream for two hours. Near unity faradaic efficiency was observed for $\mathrm{H}_{2}$ production for all samples. The faradaic efficiency values for $\mathrm{Cl}_{2}$ production for five 
different $\mathrm{BiVO}_{4} / \mathrm{WO}_{3}$ samples are provided in Supplementary Table 1. For the best performing $\mathrm{BiVO}_{4} / \mathrm{WO}_{3}$ electrode, a photocurrent-to- $\mathrm{Cl}_{2}$ faradaic efficiency of $85 \%$ was observed, with an average faradaic efficiency of $74 \%$, the highest reported to date for a stable low-cost system utilizing earth abundant materials (Supplementary Table 2). The absence of measurable $\mathrm{O}_{2}$ in the anode compartment indicates that the sub- $100 \%$ ( $74 \%$ averaged over $5 \mathrm{BiVO}_{4} / \mathrm{WO}_{3}$ electrodes) faradaic efficiency obtained for $\mathrm{Cl}_{2}$ production is likely due to the manual sampling method. This was further corroborated by measuring faradaic efficiency of the process in dark using $\mathrm{Pt}$ as the working electrode. Under similar operating conditions (i.e. at $\mathrm{pH} 1 \mathrm{NaCl}$ at $2 \mathrm{mAcm}^{-2}$ ), the $\mathrm{Pt}$ electrodes yielded an average faradaic efficiency of $76 \%$ for chlorine production nearly identical to that of the $\mathrm{BiVO}_{4} / \mathrm{WO}_{3}$ photoanodes (Supplementary Table 1).

\section{Discussion}

We have reported a facile approach to photoelectrochemically generate $\mathrm{Cl}_{2}$ using nanostructured $\mathrm{BiVO}_{4} / \mathrm{WO}_{3}$ photoanodes. We demonstrated that the electrodeposited amorphous $\mathrm{WO}_{3}$ layer could protect the $\mathrm{BiVO}_{4}$ from corrosion in acidic chloride media while facilitating efficient transport of holes to the electrolyte for chloride oxidation. A high photocurrent-to- $\mathrm{Cl}_{2}$ faradaic efficiency of $85 \%$ was observed for the best device with a photocurrent density of $2.8 \mathrm{mAcm}^{-2}$ and a photovoltage of $750 \mathrm{mV}$. This work demonstrates that simple scalable process can be utilized to produce $\mathrm{Cl}_{2}$ and $\mathrm{H}_{2}$ using sustainable light absorber and stabilization materials. Exploration of this and other PEC systems could open up a new avenue for a more economically competitive means of solar $\mathrm{H}_{2}$ production.

\section{Methods \\ Material list. Florine doped tin oxide (FTO, $7 \Omega \mathrm{sq}$ ), Acetone (HPLC grade),} Methanol (HPLC grade), Isopropanol (HPLC grade), Sodium sulfite (ACS reagent grade), Potassium phosphate monobasic $(>99 \%)$, nitric acid $\left(\mathrm{HNO}_{3}, 69 \%\right)$, and sodium hydroxide $(\mathrm{NaOH}, 98.8 \%)$ were ordered from Fisher scientific. Bismuth nitrate pentahydrate $\left(\mathrm{BiNO}_{3} 5 \mathrm{H}_{2} \mathrm{O}, 99.99\right)$, p-benzoquinone (99.5\%), vanadium acetylacetonate (98\% Sigma), Tungsten powder $(99.9 \%)$, peroxide (30\%), hydrochloric acid $(37 \%)$ sodium thiosulfate pentahydrate $(99.5 \%$ acs reagent grade), Iodine (>99.8\%), were ordered from Sigma-Aldrich. Anhydrous ethanol was purchased from Decon labs. Peroxide test strips were ordered from EMD Millipore. All solutions were prepared using $18 \mathrm{M} \Omega$ water.

Bismuth vanadate synthesis. The bismuth vanadate photo anodes were synthesized following a previously published procedure ${ }^{17}$. The $\mathrm{pH}$ of a $50 \mathrm{~mL} 0.4 \mathrm{M} \mathrm{KI}$ solution was adjusted to 1.7 using dilute $\mathrm{HNO}_{3}$. $\mathrm{BiNO}_{3} 5 \mathrm{H}_{2} \mathrm{O}$ was added to make a $0.04 \mathrm{mM}$ solution. A $10 \mathrm{~mL}$ solution of $0.23 \mathrm{M}$ p-benzoquinone dissolved in anhydrous ethanol was added and stirred for $30 \mathrm{~min}$. Prior to electrodeposition FTO was cleaned by ultrasonication in acetone, methanol, and isopropanol and dried with a stream of nitrogen. Electrodeposition of BiOI on the FTO working electrode was carried out using a VSP-300 Biologic multichannel potentiostat. A Pt coil and saturated $\mathrm{Ag} / \mathrm{AgCl}$ were used as counter and reference electrodes respectively. The deposition was conducted by applying a bias of $-0.1 \mathrm{~V}$ vs the reference electrode until $130 \mathrm{mC} ; \mathrm{cm}^{-2}$ of charge was passed. After rinsing with water the samples were dried with $\mathrm{N}_{2}$ and then placed in a muffle furnace. $150 \mu \mathrm{L}$ of $0.2 \mathrm{M}$ vanadium acetylacetonate dissolved in DMSO was drop casted on each film. The samples were then annealed at $450^{\circ} \mathrm{C}$ for $2 \mathrm{~h}$ with a temperature ramp of $2^{\circ} \mathrm{C} \mathrm{min}-1$. Excess vanadium oxide was removed via gentle stirring in $1 \mathrm{M} \mathrm{NaOH}$ for $15 \mathrm{~min}$.

Tungsten oxide deposition. Tungsten oxide was electrochemically deposited based on previously published process ${ }^{20}$. The $\mathrm{WO}_{3}$ electrodeposition solution was prepared by dissolving $0.93 \mathrm{~g}$ of tungsten powder in $10 \mathrm{~mL}$ of $30 \%$ peroxide. After dissolution, platinum coils were used to decompose excess peroxide which was confirmed with peroxide test strips. The stock solution was subsequently diluted to $100 \mathrm{~mL}$ using 65:35 $\mathrm{H}_{2} \mathrm{O}$ IPA solution, allowed to age for one week while stored in a fridge. The deposition was carried using a $\mathrm{BiVO}_{4} \mathrm{WE}, \mathrm{Pt}$ coil $\mathrm{CE}$ and saturated $\mathrm{Ag} / \mathrm{AgCl}$ reference electrode. A bias of $-0.5 \mathrm{~V}$ vs $\mathrm{Ag} / \mathrm{AgCl}$ was applied until the desired charge density was passed. The samples were then rinsed with IPA then $\mathrm{H}_{2} \mathrm{O}$ then dried in a muffle furnace at $275^{\circ} \mathrm{C}$ for $10 \mathrm{~min}$.

Photoelectrochemical characterization. All photoelectrochemical measurements were carried out in a 2-compartment quartz cell. The $\mathrm{BiVO}_{4} \mathrm{WE}$ and $\mathrm{Ag} / \mathrm{AgCl} \mathrm{RE}$ were separated from the Pt coil $\mathrm{CE}$ by a glass frit. The $\mathrm{BiVO}_{4}$ active area of $0.12 \mathrm{~cm}^{-2}$ was masked off using $3 \mathrm{M}$ electrodeposition tape and the area was confirmed using imagej software.

For J-V and stability measurements $\mathrm{BiVO}_{4}$ was illuminated through the FTO back contact via simulated sunlight from a 300W Xenon arc lamp fitted with an IR and AM 1.5 filter. A NIST certified Newport 919P-03-10 thermopile detector was used to confirm a final light intensity of $100 \mathrm{mWcm}^{-2}$. J-V plots were constructed by sweeping from the open circuit potential at a rate of $20 \mathrm{mVs}^{-1}$. For repeated sweeps a rest period of $30 \mathrm{~s}$ was taken between sweeps before returning to the open circuit voltage. Baseline measurements were performed in $1 \mathrm{M}$ sodium sulfite hole scavenger with $0.5 \mathrm{M}$ phosphate buffer with a $\mathrm{pH}$ adjusted to 7.4. Chlorine oxidation was carried out in a $4 \mathrm{M} \mathrm{NaCl}$ solution with its $\mathrm{pH}$ adjusted to 1 using hydrochloric acid. Results were plotted in comparison to the reversible hydrogen electrode using the following equation: $V_{R H E}=V_{\text {AgAgcl }}+0.197 \mathrm{~V}+0.059 \mathrm{VpH}$.

IPCE measurements were carried out using Oriel 69052 Spectral Luminator to provide monochromatic light $\pm 10 \mathrm{~nm}$ in intervals of $10 \mathrm{~nm}$ from 400 to $550 \mathrm{~nm}$. The intensity at each wavelength was measured using a silicon photodiode. Current density was measured at a constant bias of $1.42 \mathrm{~V}_{\mathrm{RHE}}$ in $4 \mathrm{M} \mathrm{NaCl} \mathrm{pH} 1$ solution.

Stability and product analysis. Stability tests were conducted by applying a constant bias of $1.42 \mathrm{~V}_{\mathrm{RHE}}$ (standard redox potential for chlorine evolution). Each compartment of the quartz cell was purged with helium for $1 \mathrm{~h}$ prior to measurements. Hydrogen and oxygen were measured by extracting $250 \mathrm{uL}$ of headspace and injecting it into an SRI 8610C GC with a Mol Sieve5A column equipped with a helium ionization detector. After the experiment the compartment housing the bismuth vanadate working electrode was gently purged with helium which passed through a potassium iodide trap solution in order to collect chlorine which was quantitatively measured via iodometric titration with sodium thiosulfate using starch as an indicator ${ }^{31}$.

Sample characterization. Structural characterization was carried out using Hitachi S-4800 SEM. UV-vis measurements were carried out using a thermo scientific evolution 300 UV-vis spectrophotometer. XPS analysis was carried out using ULVAC-PHI PHI 5000 VersaProbe II with concentric hemispherical electron energy analyzers combined with the established multi-channel detector (MCD). The incident radiation monochromatic Al Ka X-ray $(1486.6 \mathrm{eV}$ ) at 150W (accelerating voltage $15 \mathrm{kV}$, emission current $10 \mathrm{~mA}$ ) was projected $45^{\circ}$ to the sample surface and the photoelectron data was collected at takeoff angle of $\theta=90^{\circ}$. The spectra were calibrated using adventitious carbon C 1 s peak at $284.8 \mathrm{eV}$. The base pressure in the analysis chamber was maintained at $1.0 \times 10^{-7}$ torr. Low energy electrons were used for charge compensation to neutralize the sample. Survey scans were taken at pass energy of $117.4 \mathrm{eV}$, and carried out over $1200 \mathrm{eV} \sim-0 \mathrm{eV}$ binding energy range with $0.3 \mathrm{eV}$ steps and a dwell time of $30 \mathrm{~ms}$. High resolution scans of Bi $4 \mathrm{f}, \mathrm{V} 2 \mathrm{p}, \mathrm{W} 4 \mathrm{f}$ and $\mathrm{O} 1 \mathrm{~s}$ were taken at pass energy of $25.3 \mathrm{eV}$ with 0.05 $\mathrm{eV}$ steps and a dwell time of $30 \mathrm{~ms}$. TEM and EDS analyses were performed using FEI Titan Themis $\mathrm{Z}$ instrument equipped with image-and probe-forming spherical aberration (Cs) corrector. TEM samples were sonicated in ethanol and then dropped onto holey carbon TEM grids for analysis. HRTEM images were acquired at an accelerating voltage of $300 \mathrm{kV}$. EDS collection was conducted using a fourquadrant FEI Super-X detector. (30 $\mathrm{mm}^{2}$ each).

\section{Data availability}

The data presented in this work is available upon request from the corresponding author.

Received: 4 December 2018 Accepted: 12 April 2019

Published online: 22 May 2019

\section{References}

1. Maeda, K. \& Domen, K. Photocatalytic water splitting: recent progress and future challenges. J. Phys. Chem. Lett. 1, 2655-2661 (2010).

2. Khaselev, O. et al. A monolithic photovoltaic-photoelectrochemical device for hydrogen production via water splitting. Science 280, 425-427 (1998).

3. Young, J. L. et al. Direct solar-to-hydrogen conversion via inverted metamorphic multi-junction semiconductor architectures. Nat. Energy 2, 17028 (2017).

4. Shaner, M. R., Atwater, H. A., Lewis, N. S. \& McFarland, E. W. A comparative technoeconomic analysis of renewable hydrogen production using solar energy. Energy Environ. Sci. 9, 2354-2371 (2016).

5. Sayama, K. Production of high-value-added chemicals on oxide semiconductor photoanodes under visible light for solar chemical-conversion processes. ACS Energy Lett. 3, 1093-1101 (2018).

6. Karlsson, R. K. B. \& Cornell, A. Selectivity between oxygen and chlorine evolution in the chlor-alkali and chlorate processes. Chem. Rev. 116, $2982-3028$ (2016). 
7. McCrory, C. C. L., Jung, S., Peters, J. C. \& Jaramillo, T. F. Benchmarking heterogeneous electrocatalysts for the oxygen evolution reaction. J. Am. Chem. Soc. 135, 16977-16987 (2013).

8. Melián-Martel, N., Sadhwani, J. J. \& Ovidio Pérez Báez, S. Saline waste disposal reuse for desalination plants for the chlor-alkali industry: the particular case of pozo izquierdo SWRO desalination plant. Desalination 281, 35-41 (2011).

9. Porter, M. E. \& van der Linde, C. Toward a new conception of the environment-competitiveness relationship. J. Econ. Perspect. 9, 97-118 (1995).

10. Schulte, L. D., FitzPatrick, J. R., Salazar, R. R., Schake, B. S. \& Martinez, B. T. Cleanup of hydrochloric ACID waste streams from actinide processes using extraction chromatography. Sep. Sci. Technol. 30, 1833-1847 (1995).

11. O'Brien, T. F., Bommaraju, T. V. \& Hine, F. Handbook of Chlor-alkali Technology (Springer, Boston, MA 2005).

12. Luo, W. et al. Solar hydrogen generation from seawater with a modified $\mathrm{BiVO}_{4}$ photoanode. Energy Environ. Sci. 4, 4046-4051 (2011).

13. Liu, Z. et al. Efficient solar-to-chemical conversion with chlorine photoanode. Electrochem. Commun. 67, 69-72 (2016).

14. Iguchi, S., Miseki, Y. \& Sayama, K. Efficient hypochlorous acid (HClO) production via photoelectrochemical solar energy conversion using a $\mathrm{BiVO}_{4}$ based photoanode. Sustain. Energy Fuels 2, 155-162 (2018).

15. Cooper, J. K. et al. Electronic structure of monoclinic $\mathrm{BiVO}_{4}$. Chem. Mater. 26, 5365-5373 (2014).

16. Tan, H. L., Amal, R. \& Ng, Y. H. Alternative strategies in improving the photocatalytic and photoelectrochemical activities of visible light-driven $\mathrm{BiVO}_{4}$ : a review. J. Mater. Chem. A 5, 16498-16521 (2017).

17. Kim, T. W. \& Choi, K.-S. Nanoporous $\mathrm{BiVO}_{4}$ photoanodes with dual-layer oxygen evolution catalysts for solar water splitting. Science 343, 990-994 (2014).

18. Kuang, Y. et al. A front-illuminated nanostructured transparent $\mathrm{BiVO}_{4}$ photoanode for $>2 \%$ efficient water splitting. Adv. Energy Mater. 6, 1501645 (2016).

19. Demiryont, H. \& Nietering, K. E. Tungsten oxide films by reactive and conventional evaporation techniques. Appl. Opt. 28, 1494-1500 (1989).

20. Coridan, R. H., Shaner, M., Wiggenhorn, C., Brunschwig, B. S. \& Lewis, N. S. Electrical and photoelectrochemical properties of $\mathrm{WO}_{3} / \mathrm{Si}$ tandem photoelectrodes. J. Phys. Chem. C 117, 6949-6957 (2013).

21. Shaner, M. R. et al. Photoelectrochemistry of core-shell tandem junction $\mathrm{n}-\mathrm{p}^{+}-\mathrm{Si} / \mathrm{n}-\mathrm{WO}_{3}$ microwire array photoelectrodes. Energy Environ. Sci. 7, 779-790 (2014).

22. Hill, J. C. \& Choi, K.-S. Effect of electrolytes on the selectivity and stability of n-type $\mathrm{WO}_{3}$ photoelectrodes for use in solar water oxidation. J. Phys. Chem. C 116, 7612-7620 (2012)

23. Mi, Q., Zhanaidarova, A., Brunschwig, B. S., Gray, H. B. \& Lewis, N. S. A quantitative assessment of the competition between water and anion oxidation at $\mathrm{WO}_{3}$ photoanodes in acidic aqueous electrolytes. Energy Environ. Sci. 5, 5694-5700 (2012)

24. Vasilopoulou, M. et al. Hydrogenated under-stoichiometric tungsten oxide anode interlayers for efficient and stable organic photovoltaics. J. Mater. Chem. A 2, 1738-1749 (2014).

25. Lee, D. K. \& Choi, K.-S. Enhancing long-term photostability of $\mathrm{BiVO}_{4}$ photoanodes for solar water splitting by tuning electrolyte composition. Nat. Energy 3, 53-60 (2018).

26. Mase, K., Yoneda, M., Yamada, Y. \& Fukuzumi, S. Efficient photocatalytic production of hydrogen peroxide from water and dioxygen with bismuth vanadate and a Cobalt(II) chlorin complex. ACS Energy Lett. 1, 913-919 (2016).

27. Toma, F. M. et al. Mechanistic insights into chemical and photochemical transformations of bismuth vanadate photoanodes. Nat. Commun. 7, 12012 (2016).
28. Martin, D. J., Reardon, P. J. T., Moniz, S. J. A. \& Tang, J. Visible light-driven pure water splitting by a nature-inspired organic semiconductor-based system. J. Am. Chem. Soc. 136, 12568-12571 (2014).

29. Seabold, J. A. \& Choi, K.-S. Effect of a cobalt-based oxygen evolution catalyst on the stability and the selectivity of photo-oxidation reactions of a $\mathrm{WO}_{3}$ photoanode. Chem. Mater. 23, 1105-1112 (2011).

30. Augustynski, J., Solarska, R., Hagemann, H. \& Santato, C. Nanostructured thin-film tungsten trioxide photoanodes for solar water and sea-water splitting. Proc. SPIE 6340, U140-U148 (2006).

31. Rice, E. W., Baird, R. B. \& Eaton, A. D. Standard Methods for the Examination of Water and Wastewater 23rd edn (American Water Works Association, 2017).

\section{Acknowledgements}

This work was partially supported by Desalination and Water Purification Research and Development Program, Bureau of Reclamation under Agreement No. R16AC00126. W. C. is grateful for the support by The University of Iowa through Sponsored Research Agreement with HyperSolar Inc., under grant number 18786500. S.M. and A.R. also acknowledge the support of the University of Iowa start-up funds. The authors would like to acknowledge the University of Iowa Central Microscopy Research Facility for use of the Hitachi S-4800 Scanning Electron Microscopes purchased with funding from the NIH sig grant 1 S10 RR022498-01. The authors would also like to acknowledge Dr. David Cwiertny for assistance with gas analysis and use of the UV-Vis instrument.

\section{Author contributions}

S.M. and A.R. designed the experiments with assistance from W.C. J.L., J.K., J.C., A.H.G., and A.M. A.R., W.C., and A.M. prepared samples. A.R. and A.M performed PEC measurements. A.R., J.K, and J.C. designed the cell set-up and carried out product analysis measurements. G.A., C.S.K., W.I.P., H.J. A.R., J.L., and W.C. conducted material characterization. S.M. and A.R. wrote the manuscript with feedback from all authors.

\section{Additional information}

Supplementary information accompanies this paper at https://doi.org/10.1038/s42004019-0156-x.

Competing interests: The authors declare no competing interests.

Reprints and permission information is available online at http://npg.nature.com/ reprintsandpermissions/

Publisher's note: Springer Nature remains neutral with regard to jurisdictional claims in published maps and institutional affiliations.

Open Access This article is licensed under a Creative Commons Attribution 4.0 International License, which permits use, sharing, adaptation, distribution and reproduction in any medium or format, as long as you give appropriate credit to the original author(s) and the source, provide a link to the Creative Commons license, and indicate if changes were made. The images or other third party material in this article are included in the article's Creative Commons license, unless indicated otherwise in a credit line to the material. If material is not included in the article's Creative Commons license and your intended use is not permitted by statutory regulation or exceeds the permitted use, you will need to obtain permission directly from the copyright holder. To view a copy of this license, visit http://creativecommons.org/ licenses/by/4.0/

(C) The Author(s) 2019 